\title{
THE TOTAL POLYPHENOLIC CONTENT AND ANTIOXIDANT PROPERTIES OF VARIOUS HONEY AND SUGARS
}

\author{
CHAIYAVAT CHAIYASUT ${ }^{1}$, PERIYANAINA KESIKA ${ }^{1}$, SARTJIN PEERAJAN ${ }^{2}$, BHAGAVATHI SUNDARAM \\ SIVAMARUTHI ${ }^{1 *}$
}

\begin{abstract}
${ }^{1}$ Innovation Center for Holistic Health, Nutraceuticals and Cosmeceuticals, Faculty of Pharmacy, Chiang Mai University, Chiang Mai-50200, Thailand. ${ }^{2}$ Health Innovation Institute, Chiang Mai-50200, Thailand. Email: sivasgene@gmail.com
\end{abstract}

Received: 10 January 2018, Revised and Accepted: 07 February 2018

ABSTRACT

Objective: Honey and sugars are rich in polyphenols and known for several health benefits. The quality of the honey varied on the floral source and geographical region. The sugar quality depends on the processing and source. The study aimed to evaluate the total polyphenolic content and antioxidant properties of selected Thai honey and sugar samples.

Methods: Total polyphenol content and antioxidant properties were determined by the colorimetric method, and 2, 2 '-azino-bis-3-ethylbenzthiazoline6-sulfonic acid, ferric reducing antioxidant potential (FRAP), and ferrous ion-chelating assays, respectively.

Results: The honey from Eupatorium odoratum Linn (HEO) ( $0.75 \mathrm{mg}$ gallic acid equivalent/ml of sample), and meal cane sugar (MCS) (4.13 mg gallic acid equivalent/g of sample) exhibited higher polyphenol content among the honey, and sugar samples, respectively. The refined sugar (RS) showed least phenolic content ( $0.02 \mathrm{mg}$ gallic acid equivalent/g of sample) when compared to all tested sugars and honey samples. HEO exhibited high Trolox equivalent antioxidant capacity (TEAC; 235.93 mg TEAC per ml sample) among the honey samples. Among the sugars, MCS showed high TEAC (3891.22 mg TEAC per g sample). The honey from Nephelium lappaceum Linn and HEO has superior FRAP value and chelating power, respectively. The RS was least in total antioxidant capacity, FRAP, and chelating power

Conclusion: The HEO, and MCS and palm sugars are harbored with phenolic content and antioxidants. The refining process drastically diminished the quality of the sugar. The information may help to choose best carbon source for the preparation of fermented beverages with improved functional properties.

Keywords: Antioxidant, 2, 2'-azino-bis-3-ethylbenzthiazoline-6-sulfonic acid, Ferric reducing antioxidant potential, Phenolic compound, Sugars, Thai honey.

(C) 2018 The Authors. Published by Innovare Academic Sciences Pvt Ltd. This is an open access article under the CC BY license (http://creativecommons. org/licenses/by/4. 0/) DOI: http://dx.doi.org/10.22159/ajpcr.2018.v11i5.24696

\section{INTRODUCTION}

Honey is a natural product with several nutritional and pharmacological properties that are gained from the nectar of flowers. The nectar of flowers is collected by the honeybees and mixed with enzymes of bees that break down the complex sugar molecules into fructose and glucose. The honey is rich in proteins, sugars, vitamins, lipids, and volatile aromatic compounds [1,2].

A typical U.S honey composed of higher sugars (1.4\%), glucose (30.3\%), fructose $(38.4 \%)$, sucrose $(1.3 \%)$, other disaccharides $(7.3 \%)$, gluconic acid $(0.57 \%)$, other acids $(0.43 \%)$, and lactones $(0.14 \%)$, minerals such as sulfur, potassium, manganese, magnesium, chlorine, calcium, phosphorus, sodium, iron, copper $(0.17 \%)$, nitrogen $(0.04 \%)$, vitamins, and water $(17.2 \%)$ [3]. The rich antioxidant compounds (catalase, glucose oxidase, peroxidase, and polyphenolic compounds) present in honey are attributed to several health benefits (to treat burns, asthma, chronic wounds, gastrointestinal illness, and skin problems) [4].

Honey has been reported for several health benefits such as antioxidant, antibacterial, anti-inflammatory, antifungal, hypoglycemic, hepatoprotective, reproductive, gastroprotective, wound healing, anti-obesity, and immunomodulatory activities [5-16]. The quality and quantity of the honey vary based on the source of nectar, plant compounds, microbial load, honey processing, and storage conditions [2]. The quality regarding antioxidant capacity, antimicrobial property, and composition of the honey may also vary based on the geographical region and species of honeybees.
Even though sugars, especially refined sugars (RSs) are unhealthy for human consumption, it is a certain food component. The sugars are made from several sources such as sugarcane, palm, and coconut and are available in different forms. The palm sugar (PS) syrup composed of sucrose $(37.8 \%)$, glucose $(9.50 \%)$, fructose $(4.80 \%)$, monohydrate lactose $(<0.50 \%)$, maltose $(<0.50 \%)$, Vitamins (A, D, E, K, C, B1-3, B6, $\mathrm{B} 9$, and B12), and minerals ( $\mathrm{Cu}, \mathrm{Fe}, \mathrm{Mn}, \mathrm{Zn}, \mathrm{Ni}, \mathrm{Ca}, \mathrm{Mg}, \mathrm{Na}$, and $\mathrm{K}$ ) [17]. The composition of PS and its derivatives are also found to differ among the cultivars [18]. The composition of granulated cane sugar is also diverged and depends on the cultivars, processing, etc. [19].

Several studies have reported about the composition, antimicrobial, and antioxidant activity of different source of honey and sugars $[3,4,17,19-25]$. Comparative studies on total phenolic content and antioxidant capacity of selected Thai honey and different sugars were not available. The information from the present study may help to choose excellent sugar source for the development of high-quality foods.

\section{METHODS}

Sample collection

Honey (honey from Hevea brasiliensis Muell. Arg. [HHB], honey from Sesamum indicum Linn. [HSI], honey from Eupatorium odoratum Linn. [HEO], honey from Helianthus annuus Linn. [HHA], honey from Nephelium lappaceum Linn. [HNL], and honey from Dimocarpus longan Lour. ssp. [HDL]) and sugar (soft brown sugar [SBS], RS, meal cane sugar [MCS], coconut sugar [CS], cube cane sugar [CCS], PS, and crystalline 
sugar [CS]) samples were collected from Agricultural Extension and Development Center, Chiang Mai, and local market of Chiang Mai, respectively.

\section{Determination of total polyphenolic content}

The total phenolic content of the samples was determined by the modified Folin-Ciocalteu colorimetric method as described previously $[26,27]$. The absorbance was measured at $725 \mathrm{~nm}$ after 30 min incubation at room temperature (RT). The total phenolic content was represented as mg gallic acid equivalents per $\mathrm{g}$ or $\mathrm{ml}$ of sample.

\section{Total antioxidant capacity (TAC)}

TAC was calculated by 2, 2'-azino-bis-3-ethylbenzthiazoline-6-sulfonic acid (ABTS) assay as detailed formerly [28,29]. Quercetin, Trolox, and Vitamin-C were used as standards. The results were represented as mg of quercetin equivalent antioxidant capacity (QEAC), mg of Trolox equivalent antioxidant capacity (TEAC), and mg of Vitamin-C equivalent antioxidant capacity (VCEAC) per g or $\mathrm{ml}$ of sample.

Ferric reducing antioxidant potential (FRAP) assay

The FRAP assay was performed as detailed previously [26]. In brief, $60 \mu \mathrm{l}$ of sample or standard solution was mixed with $1.8 \mathrm{ml}$ of FRAP reagent and $180 \mu \mathrm{l}$ of sterile deionized water. After 4 min of incubation at RT, the reaction mixture was analyzed using spectrophotometer at $539 \mathrm{~nm}$. The values were represented as $\mathrm{mg} \mathrm{Fe}_{2} \mathrm{SO}_{4}$ equivalents per $\mathrm{g}$ or $\mathrm{ml}$ of sample.

\section{Ferrous ion chelating assay}

The chelating property of honey and sugar samples was studied [26]. The results were expressed as chelating power $\left(\mathrm{mg} \mathrm{Fe}_{2} \mathrm{SO}_{4}\right.$ equivalents per g or $\mathrm{ml}$ of sample).

\section{Statistical analysis}

All the investigations were performed in triplicate. The values were represented as mean \pm standard deviation. Duncan's new multiple range tests determined the significant differences, at 95\% confidential level $(\mathrm{p}<0.05)$ by SPSS v.17 (Chicago, SPSS Inc, U.S.A).

\section{RESULTS AND DISCUSSION}

\section{Total polyphenol content}

The HEO $(0.75 \mathrm{mg}$ gallic acid equivalent $/ \mathrm{ml}$ of sample) and MCS ( $4.13 \mathrm{mg}$ gallic acid equivalent/g of sample) showed higher polyphenol content among the honey and sugar samples, respectively, whereas HHA and HHB contain low level of phenolic acids. Regarding sugar samples, RS showed a minimum amount of phenolic content $(0.02 \mathrm{mg}$ gallic acid equivalent/g of sample) when compared to all tested sugars and honey samples (Fig. 1). The results indicated that extensive processing of sugar had reduced the polyphenolic content, and the phenolic content was found to be significantly varied among the samples.

The botanical origin of honey majorly influences the type and concentration of phenolic compounds [30]. Al et al. [21] studied the physio-chemical property and bioactivities of 24 honey samples with a different floral origin that were collected from the various region of Romania. The results suggested that phytochemical content of the honey varied based on the origin and geographical region.

Yemeni, American, Swiss, and Iranian honey were evaluated for total phenolic content and antioxidant properties. The phenolic content of the samples was anything between 56.32 and $246.21 \mathrm{mg}$ Catechin equivalent per $100 \mathrm{~g}$ of sample. Particularly, Yemeni honey was rich in phenolic compounds than that of other honey [20]. Saxena et al. [31] studied the physiochemical, and antioxidant properties of seven commercial Indian kinds of honey. The results suggested that the antioxidant activities of honey were associated with the proline content.

Tualang, acacia, and gelam honey of Malaysia were tested for antioxidant activities, and the results suggested that the antioxidant properties were closely correlated with phytochemical constituents such as phenolic compounds and vitamins [25]. The volatile composition of different Thai honey of various floral sources, and by different honeybee species were reported, and results suggested that about 32 various volatile organic compounds were found in honey that can be used as a floral marker [2]. The results of the present study proved that HEO had high total phenolic acid content (Fig. 1) when compared to other honey samples.

The physio-chemical property of Panela, a sweetener prepared from sugar cane juice, was determined and found that panela contains 4.58-11.48 g of reducing sugar per $100 \mathrm{~g}$ of sample, potassium (229.52-1027.18 mg per $100 \mathrm{~g}$ of sample) and other minerals, and no sulfur dioxide [19]. The chemical analysis of 35 palm syrup samples revealed that they were rich in sucrose, glucose, fructose, niacin (a water-soluble vitamin), and minerals, especially potassium $(0.45 \%)$ and fat $(0.20 \%)$ [17]. The present study also evidenced that MCS and PS possess high total phenolic content when compared to RS (Fig. 1).

\section{Antioxidant capacity}

The TAC of the samples was compared with three different positive standards such as Vitamin-C, Trolox, and quercetin. The results were represented as QEAC, mg of TEAC, and mg of VCEAC. The HEO (181.75 mg VCEAC and $235.93 \mathrm{mg}$ TEAC per ml of sample) and HNL (237.37 mg TEAC and $182.86 \mathrm{mg}$ VCEAC per ml of sample) exhibited high TEAC and VCEAC, while HEO, HHA, HNL, and HDL showed a range of QEAC within significant changes. Regarding sugar samples,

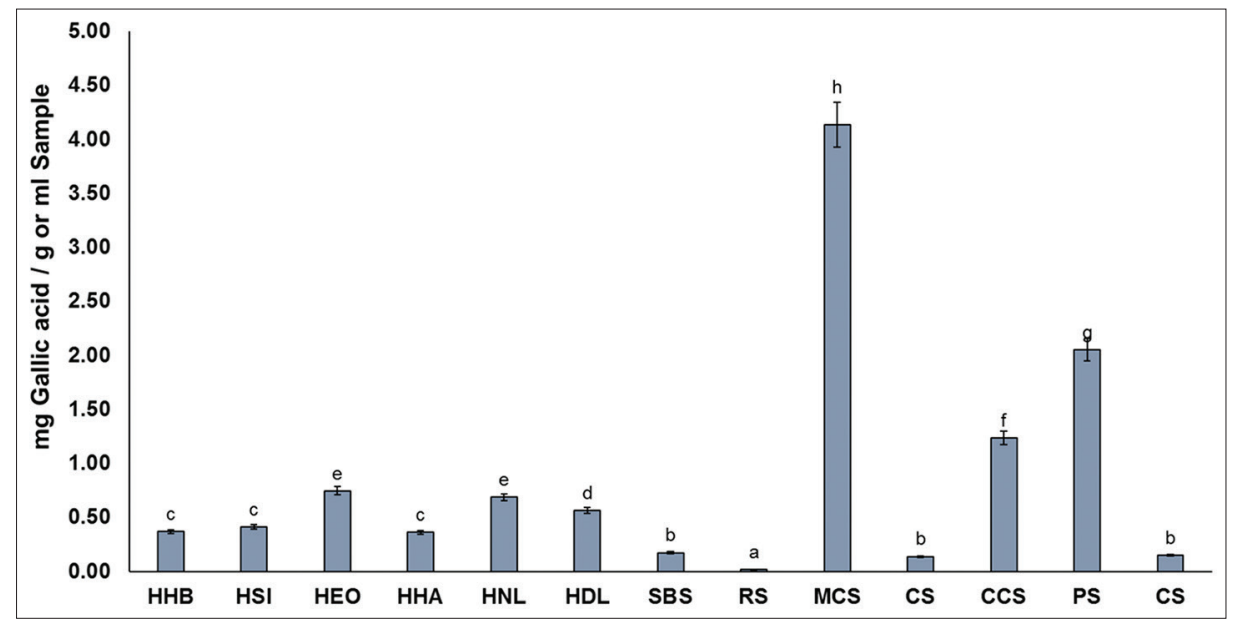

Fig. 1: The total phenolic content of studied honey and sugar samples. The results were expressed as mg gallic acid per $\mathrm{g}$ or ml of sample. $a-h$ represents the significant changes $(p>0.05)$ among the samples 
MCS displayed high TAC (2997.65 mg VCEAC, $3891.22 \mathrm{mg}$ TEAC, and $1561.67 \mathrm{mg}$ QEAC per $\mathrm{g}$ of sample) when compared to other sugar samples in all three comparisons. Apparently, RS displayed very least TAC (8.77 mg VCEAC, $11.38 \mathrm{mg}$ TEAC, and $4.57 \mathrm{mg}$ QEAC per g of sample) among the entire samples. The next to MCS, PS, and CCS showed high TAC when compared to all samples (Fig. 2). The results were found to be correlated with the total polyphenolic content of the samples. The samples that were rich in polyphenols exhibited high TAC.

The reducing power of the samples was assessed by FRAP assay. HNL showed maximum FRAP value ( $0.48 \mathrm{mg} \mathrm{FeSO}_{4} / \mathrm{ml}$ of sample) than that of the other honey samples; whereas HEO, HHA, and HDL also showed similar FRAP values (0.33-0.40 $\mathrm{mg} \mathrm{FeSO}_{4} / \mathrm{ml}$ of sample) with insignificant variations when compared to HNL. Regarding, sugar samples, MCS showed high FRAP value, $8.60 \mathrm{mg} \mathrm{FeSO}{ }_{4} / \mathrm{g}$ of sample, when compared to other samples, followed by PS, CCS, CS, and CS showed $3.20,1.30,0.42$, and $0.14 \mathrm{mg} \mathrm{FeSO} \mathrm{H}_{4} / \mathrm{g}$ of sample, respectively. RS exhibited negligible level ( $0.03 \mathrm{mg} \mathrm{FeSO} / \mathrm{g}$ of sample) of reducing power when compared to all tested samples (Fig. 3).

The chelating power assay results showed that HEO exhibits more chelating power $(272.21 \mathrm{mg} \mathrm{FeSO} / 4 \mathrm{ml}$ of sample) when compared to other honey samples. The HHA, HDL, HSI, HHB, and HNL exhibited the chelating power of about 270.64, 269.33, 268.99, 268.80, and $268.33 \mathrm{mg} \mathrm{FeSO} / 4 \mathrm{ml}$ of sample, respectively. Regarding sugars, SBS showed the maximum chelating power of about $268.55 \mathrm{mg} \mathrm{FeSO}_{4} / \mathrm{g}$ of the sample. The samples MCS, PS, CS, RS, CCS, and CS displayed 264.97, 263.93, 262.16, 261.47, 260.16, and $257.51 \mathrm{mg} \mathrm{FeSO}_{4} / \mathrm{g}$ of sample, respectively (Fig. 4). The results indicated that honey samples exhibited high chelating power than that of the sugars. Moreover, RS showed slightly higher chelating capacity than that of the other samples.

Portugal honey has been reported for its biochemical composition (sugars, phenols, flavonoids, $\beta$-carotene, lycopene, and ascorbic acid,), antioxidant activity, and antimicrobial activity against Bacillus subtilis, Klebsiella pneumoniae, Staphylococcus aureus, Staphylococcus lentus, and Escherichia coli [4,32]. A study on bioactivities of 24 honey samples revealed that honey from honeydew was rich in total phenolic content and exhibited high bioactivities. The next to honeydew, honey from sun-flower, lime, and acacia were superior in the quality when compared to other studied honey samples [21]. AlMamary et al.[20] reported that Acacia ehrenbergina honey (SalamTehamah; Yemeni honey) was greater in antioxidant activities and total phenolic content when compared to other tested Yemeni and other honey samples.
A comparative study on Thai honey and manuka honey revealed that mangosteen and rambutan honey were high in antioxidants regarding phenolic content when compared to manuka honey, even though manuka honey was rich in Vitamin C [24].

The honey from Thai stingless bee has been studied for chemical composition and bioactivities. The study proved that Thai stingless bee honey has very low diastase activity, antioxidant activity, and antimicrobial activity against 13 microbial pathogens [33]. Thai honey from longan flower exhibited high antimicrobial activity against methicillin-resistant $S$. aureus. The coffee pollen honey showed high flavonoids and phenolic content and exhibited high antioxidant activity. The tyrosinase inhibition activity (63.5\% of inhibition) has been recorded in coffee flower honey [23]. The results of the present study also proved that honey sample that is rich in phenolic content exhibited high antioxidant activity.

The ice cream made with unrefined cane sugar exhibited high antioxidant activity and is mostly accepted and preferred by the individual panel during the study period than that of the RS counterpart [34]. It has been proved that raw cane sugar, plant syrups, molasses, and fruit sugars were rich in antioxidants and these sugars are the best alternative for RS [35]. A study on the chemical composition of granulated PS from the sap of nipa palm suggested that nipa PS was safe regarding reducing sugar content to maintain the constant blood sugar level. The sucrose, fat, and potassium content was found to be higher in nipa PS [18]. The results of the present study also proved that RS possess very low active compounds regarding total phenolic compounds, and exhibiting poor antioxidant activity when compared to other tested sugars.

\section{CONCLUSION}

The present study was an attempt to reveal the phenolic content and antioxidant property of commonly used honey and sugars in the preparation of fermented plant beverages of northern Thailand. The results revealed that HEO contains high phenolic compounds, and exhibits high antioxidant capacity. The MCS and PSs were found to be superior in quality regarding free radical scavenging activity and polyphenolic content. The RS exhibited least antioxidant activity correlated with less phenolic content. The information acquired from this study may help to select best carbon source for the preparation of fermented beverages with improved functional properties.

\section{ACKNOWLEDGMENT}

Authors gratefully acknowledge the Chiang Mai University grant (CMU-grant) for the support and also acknowledge the Faculty of

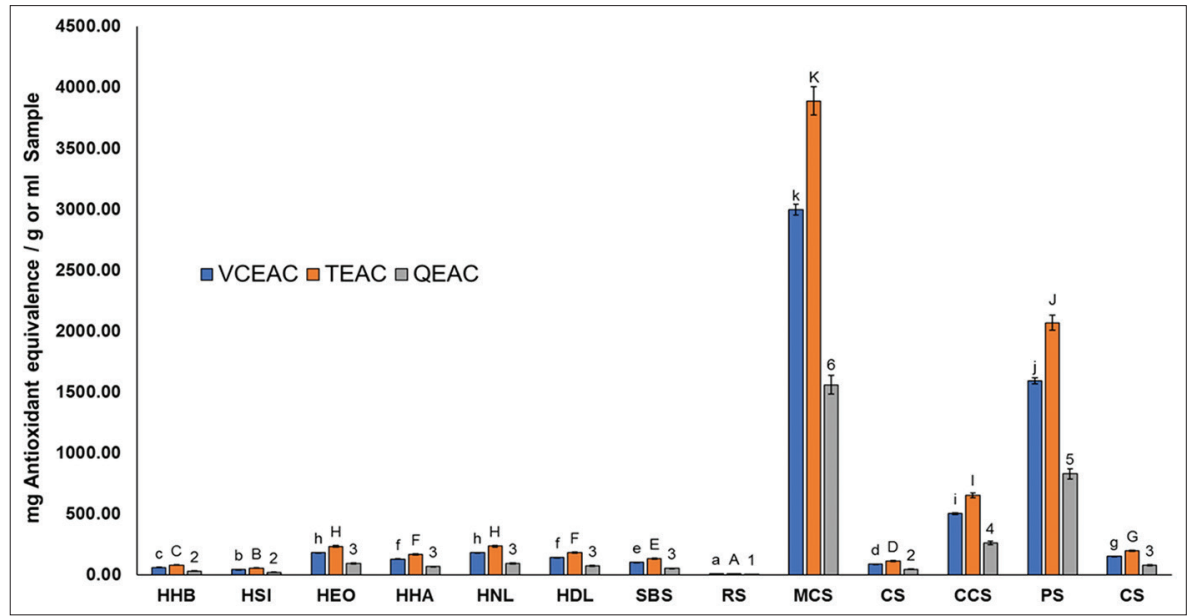

Fig. 2: The total antioxidant capacity (TAC) of the samples. TAC of samples was compared with various standards, and the results were represented as mg of quercetin equivalent antioxidant capacity, $\mathrm{mg}$ of Trolox equivalent antioxidant capacity, and mg of Vitamin-C equivalent antioxidant capacity per $\mathrm{g}$ or $\mathrm{ml}$ of sample. a-k, A-K, and 1-6 indicate the significant changes (p>0.05) among the samples 


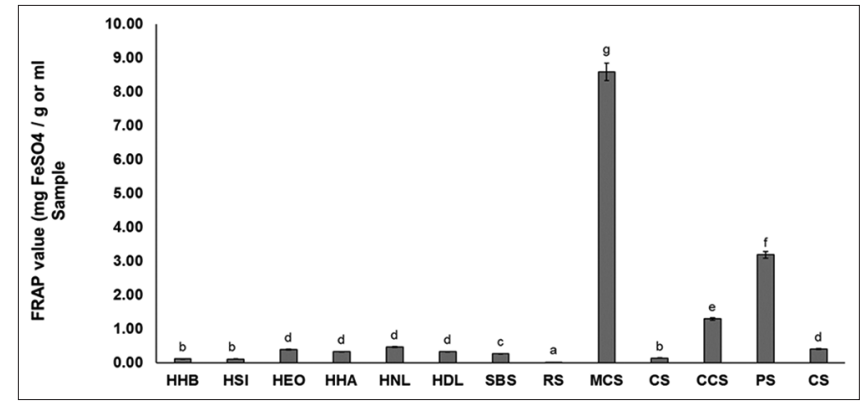

Fig. 3: The FRAP values ( $\mathrm{mg} \mathrm{FeSO}_{4}$ per $\mathrm{g}$ or $\mathrm{ml}$ of sample) of honey and sugar samples. a-h represents the significant changes ( $p>0.05$ ) among the samples

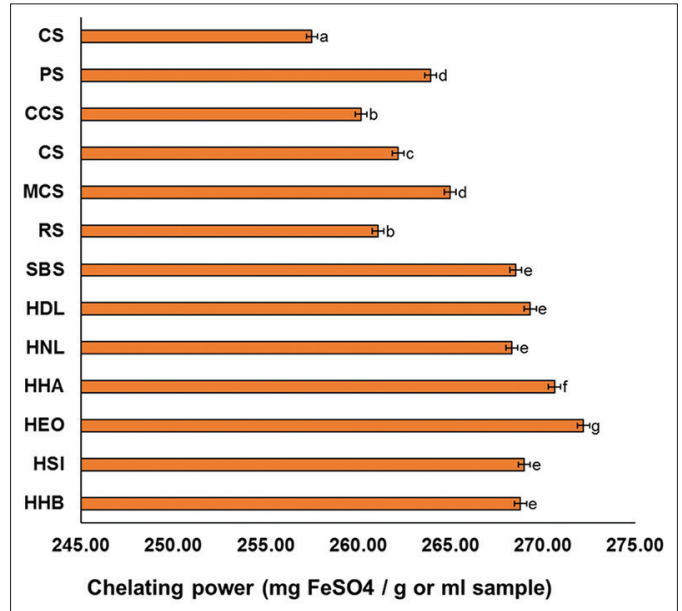

Fig. 4: The chelating power ( $\mathrm{mg} \mathrm{FeSO}{ }_{4}$ per $\mathrm{g}$ or $\mathrm{ml}$ of sample) of honey and sugar samples. a- $h$ represents the significant changes ( $>>0.05$ ) among the samples

Pharmacy, and Chiang Mai University, Thailand, for the necessary provision.

\section{CONFLICT OF INTEREST}

There is no conflict of interest.

\section{AUTHOR'S CONTRIBUTIONS}

CC involved in the study design, experiments, review, and finalization of the manuscript. BSS and PK contributed to data analysis, manuscript preparation and critical revision of the manuscript. SP is responsible for wet lab experiments, data collection, and analysis. All the authors agree with the content of the manuscript.

\section{REFERENCES}

1. Al-Qassemi R, Robinson R. Some special nutritional properties of honey-a brief review. Nutr Food Sci 2003;33:254-60.

2. Pattamayutanon P, Angeli S, Thakeow P, Abraham J, Disayathanoowat T, Chantawannakul P. Volatile organic compounds of Thai honeys produced from several floral sources by different honey bee species. PLoS One 2017;12:e0172099.

3. Ball DW. The chemical composition of honey. J Chem Educ 2007;84:1643-6.

4. Ferreira IC, Aires E, Barreira JC, Estevinho LM. Antioxidant activity of Portuguese honey samples: Different contributions of the entire honey and phenolic extract. Food Chem 2009;114:1438-43.

5. Erejuwa OO, Gurtu S, Sulaiman SA, Ab Wahab MS, Sirajudeen KN, Salleh MS. Hypoglycemic and antioxidant effects of honey supplementation in streptozotocin-induced diabetic rats. Int J Vitam Nutr Res 2010;80:74-82.

6. Tan HT, Rahman RA, Gan SH, Halim AS, Hassan SA, Sulaiman SA, et al. The antibacterial properties of Malaysian Tualang honey against wound and enteric microorganisms in comparison to manuka honey. BMC Complement Altern Med 2009;9:34.

7. Pratibha JS, Manita TW. Antibacterial activity of honey against ESBL producing Klebsiella pneumoniae from burn wound infections. Int J Curr Pharm Res 2015;7:32-6.

8. Kassim M, Achoui M, Mustafa MR, Mohd MA, YusoffKM. Ellagic acid, phenolic acids and flavonoids in Malaysian honey extracts demonstrate in vitro anti-inflammatory activity. Nutr Res 2010;30:650-9.

9. Koc AN, Silici S, Kasap F, Hormet-Oz HT, Mavus-Buldu H, Ercal BD. Antifungal activity of the honeybee products against Candida spp. and Trichosporon spp. J Med Food 2011;14:128-34.

10. Al-Waili NS, Saloom KY, Al-Waili TN, Al-Waili AN, Akmal M, AlWaili FS, et al. Influence of various diet regimens on deterioration of hepatic function and hematological parameters following carbon tetrachloride: A potential protective role of natural honey. Nat Prod Res 2006;20:1258-64.

11. Zaid SS, Sulaiman SA, Sirajudeen KN, Othman NH. The effects of Tualang honey on female reproductive organs, tibia bone and hormonal profile in ovariectomised rats-animal model for menopause. BMC Complement Altern Med 2011;10:82

12. Gharzouli K, Amira S, Gharzouli A, Khennouf S. Gastroprotective effects of honey and glucose-fructose-sucrose-maltose mixture against ethanol-, indomethacin- and acidified aspirin-induced lesions in the rat. Exp Toxicol Pathol 2002;54:217-21.

13. Sushanth KA, Lakshmi KC, Reddy DS. Evaluation of wound healing activity with a new formulation of dry Mangifera indica and honey using swiss albino mice. Asian J Pharm Clin Res 2016;9:139-42.

14. Arzoo, Parle M. Anti-obsessive-compulsive activity of honey. Asian J Pharm Clin Res 2017;10(5):206-9.

15. Elbakry KA, Malak CA, Howas MM. Immunomodulatory role of honey and propolis on carbon tetrachloride (CCL4) injected rats. Int J Pharm PharmSci 2015;7:259-62.

16. Yap P, Bakar MF. Physicochemical, phytochemical and antimicrobial properties of wild honey collected at mangrove and mountain areas in Sabah, Malaysian Borneo. Int J Pharm PharmSci 2014;6:287-92.

17. Luis G, Rubio C, Gutiérrez AJ, Hernández C, González-Weller D, Revert C, et al. Palm tree syrup; Nutritional composition of a natural edulcorant. Nutr Hosp 2012;27:548-52.

18. Radam RR, Sari HN, Lusyani H. Chemical compounds of granulated palm sugar made from sap of nipa palm (Nypa fruticans Wurmb) growing in three different places. J Wetlands Environ Manage 2014;2:108-14.

19. Guerra MJ, Mujica MV. Physical and chemical properties of granulated cane sugar "panelas". Cienc Tecnol Aliment Campinas 2010;30:250-7.

20. Al-Mamary M, Al-Meeri A, Al-Habori M. Antioxidant activities and total phenolics of different types of honey. Nutr Res 2002;22:1041-7.

21. Al ML, Daniel D, Moise A, Bobis O, Laslo L, Bogdanov S. Physicochemical and bioactive properties of different floral origin honeys from Romania. Food Chem 2009;112:863-7.

22. Erejuwa OO, Sulaiman SA, Wahab MS. Honey: A novel antioxidant. Molecules 2012;17:4400-23.

23. Jantakee K, Tragoolpua Y. Activities of different types of Thai honey on pathogenic bacteria causing skin diseases, tyrosinase enzyme and generating free radicals. Biol Res 2015;48:4.

24. Bundit T, Anothai T, Pattaramart P, Roongpet T, Chuleeporn S. Comparison of antioxidant contents of Thai honeys to Manuka honey. Mal J Nutr 2016:22:413-20.

25. Chua LS, Rahaman NL, Adnan NA, Tan TT. Antioxidant activity of three honey samples in relation with their biochemical components. J Anal Methods Chem 2013;2013:313798.

26. Peerajan S, Chaiyasut C, Sirilun S, Chaiyasut K, Kesika P, Sivamaruthi BS. Enrichment of nutritional value of Phyllanthus emblica fruit juice using the probiotic bacterium, Lactobacillus paracasei $\mathrm{HIIO}$ mediated fermentation. Food Sci Technol Campinas 2016;36:116-23.

27. Chaiyasut C, Kesika P, Chaiyasut K, Sittiyuno P, Peerajan S, Sivamaruthi BS. Total phenolic content and free radical scavenging activity of representative medicinal plants of Thailand. Asian J Pharm Clin Res 2017;10:137-41.

28. Sivamaruthi BS, Pengkumsri N, Saelee M, Kesika P, Sirilun S, Peerajan S, et al. Impact of physical treatments on stability and radical scavenging capacity of anthocyanidins. Int J Pharm Pharm Sci 2016;8:162-7.

29. Chaiyasut C, Sivamaruthi BS, Pengkumsri N, Sirilun S, Peerajan S, Chaiyasut $\mathrm{K}$, et al. Anthocyanin profile and its antioxidant activity of widely used fruits, vegetables, and flowers in Thailand. Asian J Pharm Clin Res 2016;9:218-24. 
30. Kucuk M, Kolayh S, Karaoglu S, Ulusoy E, Baltaci C, Candan F. Biological activities and chemical composition of three honeys of different types from Anatolia. Food Chem 2007;100:526-34.

31. Saxena S, Gautam S, Sharma A. Physical, biochemical and antioxidant properties of some Indian honeys. Food Chem 2010;118:391-7.

32. Estevinho L, Pereira AP, Moreira L, Dias LG, Pereira E. Antioxidant and antimicrobial effects of phenolic compounds extracts of Northeast Portugal honey. Food Chem Toxicol 2008;46:3774-9.

33. Suntiparapop K, Prapaipong P, Chantawannakul P. Chemical and biological properties of honey from Thai stingless bee (Tetragonula leaviceps). J Apicult Res 2012;51:45-52.

34. Low RHP, Baba AS, Aboulfazli F. Effects of different levels of refined cane sugar and unrefined coconut palm sugar on the survivability of Lactobacillus acidophilus in probiotic ice cream and its sensory and antioxidant properties. Food SciTechnol Res 2015;21:857-62.

35. Phillips KM, Carlsen MH, Blomhoff R. Total antioxidant content of alternatives to refined sugar. J Am Diet Assoc 2009;109:64-71. 